\title{
PERSPECTIVAS DE LETRAMENTO INFORMACIONAL NO BRASIL: PRÁTICAS EDUCATIVAS DE BIBLIOTECÁRIOS EM ESCOLAS DE ENSINO BÁSICO
}

PERSPECTIVES OF INFORMATION LITERACY: LIBRARIANS' EDUCATIONAL PRACTICES IN BRAZILIAN SCHOOLS

Bernadete Santos Campello Professor adjunto nível quatro da Escola de Ciência da Informação da UFMG campello@eci.ufmg.br

\section{Resumo}

A presente pesquisa tem como objetivo compreender a prática educativa de bibliotecários brasileiros que atuam em escolas de ensino básico, buscando esclarecer: se esta prática está restrita à promoção da leitura, se os bibliotecários já desenvolvem atividades de ensino de habilidades informacionais e em que medida estão contribuindo para o processo de letramento informacional dos alunos. Utilizou-se metodologia interpretativa e os dados foram coletados por meio de relatos de experiências, entrevistas e grupo de discussão. A amostra foi composta por 28 bibliotecários que atuavam em escolas de ensino básico (14 de escolas públicas e 14 de escolas particulares). Os resultados revelaram que a sensibilização e a conquista dos estudantes constituem o principal foco da prática educativa dos bibliotecários, evidenciando a predominância de ações voltadas para atrair os alunos para a biblioteca e para a leitura. A quantidade de atividades de orientação à pesquisa é bem mais modesta. Considerando-se que o letramento informacional se caracteriza pela ênfase na aprendizagem pela pesquisa orientada, pode-se concluir que, nesse sentido, a ação dos bibliotecários é incipiente.

Palavras chave: Biblioteca escolar. Bibliotecários. Função educativa. Letramento informacional.

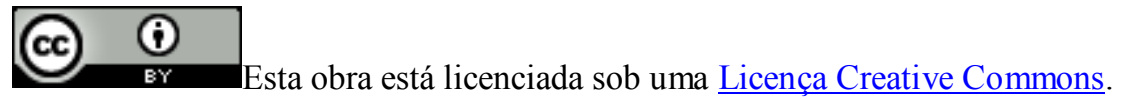

DOI 10.5007/1518-2924.2010v15n29p184

Enc. Bibli: R. Eletr. Bibliotecon. Ci. Inf., ISSN 1518-2924, Florianópolis, v. 15, n. 29, p.184-208, 2010. 


\section{INTRODUÇÃO}

Esta pesquisa trata de práticas educativas exercidas por bibliotecários que atuam em bibliotecas de ensino básico e de sua contribuição para a aprendizagem dos alunos, representando o que tem sido chamado de papel educativo do bibliotecário. Historicamente, o principal papel educativo do bibliotecário - em especial daqueles que atuam em instituições escolares - tem sido promover a leitura, isto é, desenvolver nos usuários o hábito e o prazer de ler (WOOLLS, 2006). Entretanto, com as mudanças ocorridas na sociedade em geral e na educação em particular, marcadamente a partir da década de 1990, destaca-se outra esfera de atuação do bibliotecário: educação de usuários/auxílio à pesquisa. As referidas mudanças requerem que as pessoas adquiram competências para localizar, avaliar e usar informações, o que implica, por parte dos bibliotecários, em ações mais complexas, pois as pessoas, além de tornarem-se leitores, necessitam ser competentes para aprender por meio da informação, isto é, necessitam desenvolver habilidades informacionais. Assim, as práticas de educação de usuários nas bibliotecas integram hoje a noção de letramento informacional (ALA, 1989), partindo-se do pressuposto de que o bibliotecário detém conhecimentos que ajudarão os usuários no desenvolvimento dessas habilidades, ampliando-se a função educativa desse profissional.

No Brasil, embora presente com bastante freqüência no discurso bibliotecário desde a década de 1960, a função educativa desse profissional não parece ter-se concretizado na prática (BARROS, 1987, p. 94; SALES, 2005, p. 54), havendo concordância de que o bibliotecário, mesmo reconhecendo a importância deste papel (AMBINDER et al, 2005, p. 2, MORIGI, VANZ; GALDINO, 2002, p. 141), ainda se limita a atuar na promoção da leitura e no desenvolvimento do gosto de ler (CAMPELLO, 2003). O foco da ação educativa da biblioteca escolar na leitura ficou confirmado por dois estudos de citação feitos com base em documentos da área (VIANNA; CALDEIRA, 2004; CAMPELLO et al., 2007). Em ambos, o autor mais citado foi Ezequiel Theodoro da Silva, conhecido pesquisador da área de leitura, e os rankings dos autores e textos mais citados incluíram Regina Zilberman, Marisa Lajolo, Roger Chartier, Edmir Perrotti, Maria Helena Martins, Paulo Freire (A importância do ato de ler) e Roland Barthes (O prazer do texto).

O outro espaço para a ação educativa do bibliotecário na escola - auxílio à pesquisa escolar - diz respeito a esse profissional, por constituir atividade em que o aluno se envolve, ou deveria 
envolver-se efetivamente com a busca e o uso da informação, no ambiente da biblioteca. É, portanto, a oportunidade que se oferece ao bibliotecário para exercitar prática educativa mais ampla, contribuindo para desenvolver nos alunos habilidades informacionais. Entretanto, a escassa influência do bibliotecário na aprendizagem reflete-se perceptivelmente na forma como a pesquisa escolar acontece, conforme revelado por estudos, que observaram nítida disfunção no processo. (FIALHO; MOURA, 2005, p. 205; GASQUE; TESCAROLO, 2007; MAGALHÃES, 1992, p. 181-185; NEVES, 2000, p. 161; SILVA, S. A., 1997, p. 156).

Assim, a conjunção desses dois aspectos - a ênfase que o bibliotecário dá à promoção da leitura e sua dificuldade para contribuir com a pesquisa escolar - indica que esse profissional, embora tendo consciência de seu papel educativo, não deu ainda o salto para a ação pedagógica mais ampla, que possa contribuir para a formação de usuários competentes na busca e no uso de informação.

\section{OBJETIVOS}

A presente pesquisa tem como objetivo compreender como se dá a prática educativa do bibliotecário brasileiro. Buscamos responder às seguintes questões:

A ação pedagógica dos bibliotecários brasileiros está restrita à promoção da leitura?

Bibliotecários que atuam em bibliotecas de escolas públicas e particulares já se envolvem no ensino de habilidades informacionais?

Em que medida eles estão contribuindo para o processo de letramento informacional dos alunos? Consideramos que a compreensão dessa prática pode levar ao delineamento mais preciso da função educativa do bibliotecário, já que permite a percepção de especificidades do contexto bibliotecário brasileiro, possibilitando lidar-se com a questão de maneira condizente com a realidade do país.

\section{REVISÃO DE LITERATURA}

Enc. Bibli: R. Eletr. Bibliotecon. Ci. Inf., ISSN 1518-2924, Florianópolis, v. 15, n. 29, p.184-208, 2010. 
Esta revisão compõe-se de dois tópicos (a leitura na escola e o papel educativo do bibliotecário) que serviram de base para as descrições e interpretações realizadas na análise dos dados.

\subsection{Leitura na escola}

Falar de leitura no Brasil é quase sempre falar de problemas e dificuldades, situação que Silva, E. T. (1997, p. 47) caracterizou como "soma de carências", que se relacionam inicialmente à apropriação do universo letrado por crianças e jovens em idade escolar. Segundo Edmir Perrotti (1990, p. 16), essas dificuldades estariam relacionadas à contradição entre a visão iluminista da cultura letrada e uma sociedade, como a brasileira, ligada fortemente à oralidade. $\mathrm{O}$ autor sugeriu "uma reflexão aprofundada sobre os componentes sócio-culturais que estariam na raiz da falta de leitura de crianças e jovens" (PERROTTI, 1990, p. 17), posição que é também assumida por

Ezequiel T. Silva (1997, p. 93), que tem ressaltado constantemente as questões estruturais que afetam a leitura e que se refletem na forma como ela é ensinada na escola.

Sabe-se que a escola tem contribuído para o afastamento do aluno da leitura. Segundo Silva, E. T. (1995, p. 104), as finalidades que a escola define para a leitura são "questionáveis", com o que pareceu concordar Marisa Lajolo, quando afirmou que "[...] a leitura escolarizada tem servido a propósitos de memorização de normas gramaticais, reprodução de dogmatismos, celebrações cívicas, aumento de vocabulário, motivação para a produção escrita, etc [...]” (LAJOLO, 1982, citado por SILVA, E. T., 1995, p. 104). Outra prática questionável da escola com relação à leitura é a escolha dos textos. Pesquisas revelaram o comando absoluto das situações de leitura pelo professor, a começar pela seleção de livros didáticos e outros textos, que não levava em consideração a opinião dos alunos (MAGALHÃES, 1992, p. 179; PINHEIRO, 2004, p. 118-119). Estratégias didáticas pobres se somam aos problemas acima mencionados, para compor o quadro pouco estimulante da leitura na escola, contribuindo para o afastamento do leitor do texto. Estudos mostraram que leituras em sala de aula eram relacionadas à avaliação (MAGALHÃES, 1992, p. 175), que os professores usavam basicamente o livro didático (SILVA, S. A., 1997, p. 96), transformando a literatura em “instrumento enfadonho" de aprendizagem (PACHECO, 2004, p. 210-211). Apesar de todas as interferências e dificuldades que encontravam para ler, os alunos reagiam, utilizando estratégias para escolher o que queriam ler, para superar as dificuldades e até 
para ludibriar os professores nos momentos de leitura imposta (SILVA, S. A., 1997, p. 120; MAGALHÃES, 1992, p. 175).

Parece existir uma incompatibilidade entre a experiência de ler por imposição e a experiência prazerosa de leitura, que se instala a partir de práticas de leitura rígidas, pobres e burocratizadas desenvolvidas na escola, e de impedimentos que dificultam a freqüência dos estudantes à biblioteca, observados por Silva, S. A. (1997, p. 69): “dificuldade para ausentar-se da sala de aula, falta de um horário disponível para ir à biblioteca”.

\subsubsection{Dinamização da leitura}

Dinamização é palavra recorrente no discurso da leitura e da biblioteca escolar, como solução para o desinteresse dos estudantes pela leitura. Na verdade, segundo Magalhães (1980, p. 52-55), a leitura não é atividade preferida por crianças e jovens, competindo com outras práticas culturais contemporâneas vistas como muito mais dinâmicas e atraentes. "Não é raro escutar em reuniões escolares ou em conversas informais entre colegas docentes, a necessidade de tornar o livro mais atraente e mais dinâmico por meio de recursos como jogos, dramatizações, atividades plásticas [...]" (PACHECO, 2004, p. 210). Lajolo, (1997, p. 70, 71) criticou essa necessidade de inventar atividades de leitura lúdica e criativa, que, segundo ela, podem estar camuflando uma uniformização da leitura escolar e apenas simulando criação e fantasia. A preocupação do professor com a dinamização do livro foi criticada pela autora como atitude de "idealismo ingênuo" que se soma ao "imediatismo das soluções enlatadas". Embora a considerando bem intencionada - pois busca "reduzir o atrito" e aumentar a "digestibilidade da aula" - a autora alertou para o fato de que "técnicas milagrosas de convívio harmonioso com o texto não existem" (p. 14). Segundo Lajolo (1997, p. 14), tais técnicas de dinamização podem levar o professor a lidar "superficialmente com a questão, resolvendo o problema pelo seu contorno, passando ao largo das zonas mais profundas de conflito".

Na biblioteca, a dinamização envolve duas ações específicas: transformar a biblioteca em um espaço dinâmico por meio de atividades variadas e/ou num espaço atraente, por meio de uma organização física alegre e convidativa. Nóbrega (2002 p. 129-130) aglutina esses dois tipos de ações no que chama de dinamização do acervo: atividades variadas de leitura (variedade de textos e de manifestações artísticas) e espaço convidativo. Essa dinamização se concretizaria na criação 
de ambiências de leitura, onde ocorreriam atividades planejadas de leitura. Dios (1989, p. 20), por sua vez, como responsável por uma biblioteca escolar, descreveu a dinamização como reação contra um ambiente hostil à leitura. Segundo ela "dinamizar no nosso caso significou democratizar, dar voz a todos num relacionamento horizontal, buscando ouvir, aprender conjuntamente, numa troca efetiva" (DIOS, 1989, p. 20-21).

Analisando-se as perspectivas de dinamização, conforme a visão dessas duas autoras, percebe-se que, embora com objetivos diversos, mobilizam ações semelhantes que podem modificar a imagem da biblioteca e aproximar o aluno do livro.

\subsection{O papel educativo do bibliotecário}

O papel educativo do bibliotecário pode ser exercido em vários níveis. Segundo Kuhlthau (1996, p. 145), no nível mais elementar, ele se concretiza por meio da ação organizadora, quando a biblioteca disponibiliza uma coleção estruturada de recursos informacionais e instrumentos para seu acesso. A ação educativa se limita ao fornecimento de instruções para uso desses recursos, geralmente na forma de folhetos ou textos explicativos, por meio dos quais o aluno pode aprender por conta própria alguns aspectos do funcionamento da biblioteca.

No segundo nível, o bibliotecário é o palestrante (lecturer), usando, por exemplo, a estratégia de reunir os alunos novatos no início do período letivo para dar explanações genéricas sobre o funcionamento da biblioteca (regulamentos e normas) e sobre os recursos por ela oferecidos. Ocorre, nesse caso, sobrecarga de informações factuais e geralmente superficiais. Não estando relacionado com um problema ou com uma questão de aprendizagem, esse tipo de instrução não constitui em geral experiência significativa para o aluno (KUHLTHAU, 1996, p. 148).

No terceiro nível, o bibliotecário é o instrutor (KUHLTHAU, 1996, p. 149), prestando, aos estudantes, esclarecimentos sobre o uso de determinada fonte de informação, geralmente relacionada a um tópico que o professor esteja desenvolvendo em sala de aula, ensinando-lhes, por exemplo, a usar enciclopédias para elaborar um trabalho de pesquisa. Nesse nível, torna-se necessário um mínimo de planejamento didático, pois a estratégia de aprendizagem envolve mais de um mediador (bibliotecário e professor) e o bibliotecário precisa, pelo menos, estar ciente do assunto a ser abordado para se certificar da existência e da disponibilidade de materiais adequados.

Enc. Bibli: R. Eletr. Bibliotecon. Ci. Inf., ISSN 1518-2924, Florianópolis, v. 15, n. 29, p.184-208, 2010. 
No quarto nível, o objetivo é ensinar aos alunos a localização e o uso de fontes de informação que serão usadas no estudo de determinado tópico do programa. O bibliotecário age como tutor (KUHLTHAU, 1996, p. 150), enfatizando os passos a serem seguidos durante a pesquisa e propondo um roteiro que servirá posteriormente para a execução de tarefas semelhantes. Nesse nível, a ação do bibliotecário também fica restrita ao ensino da localização das fontes e das etapas da busca, sem se envolver no processo de interpretação do texto. Há maior colaboração com o professor, já que o bibliotecário precisa conhecer o objetivo do projeto e as responsabilidades de ambos devem estar definidas com clareza. Observa-se que, nesses quatro primeiros níveis, a intervenção do bibliotecário se dá de forma limitada, sem interferência em processos mais elaborados de pensamento.

No quinto nível, a função do bibliotecário é a de orientador (counselor), o que envolve mais do que ensinar a identificar e localizar fontes e a seguir um roteiro padronizado de pesquisa. Ele auxilia o aluno também no entendimento do conteúdo das fontes de informação para responder à questão ou resolver o problema proposto no seu projeto. A complexa dinâmica que caracteriza a aprendizagem é levada em consideração e o apoio adequado para avançar é fornecido na medida da necessidade de cada aluno ou grupo. Estratégias para trabalhar o processo de pesquisa são integradas às estratégias para localizar informação, permitindo ao aluno dominar o processo para futuras aplicações. Nesse nível, o bibliotecário se torna participante ativo do processo de aprendizagem, envolvido nas fases de planejamento, implementação e avaliação (KUHLTHAU, 1996, p. 151).

Pode-se perceber que a ampliação do papel educativo do bibliotecário pressupõe colaboração constante com os professores. Nos níveis mais altos, o bibliotecário é visto como catalizador dessa colaboração, iniciando ações de relacionamento, não apenas com os professores individualmente, mas buscando criar uma cultura de colaboração na escola. Assumindo papel educativo relevante na escola, o bibliotecário exerceria liderança, no sentido de elucidar questões sobre a natureza da aprendizagem em ambiente caracterizado por abundância informacional, propiciando ação didática articulada em torno da biblioteca (AASL/AECT, 1998, p. 50-55).

A literatura mostra, portanto, que o papel educativo do bibliotecário pode-se dar de diferentes maneiras. A presente pesquisa pretendeu investigar como o bibliotecário no Brasil, por meio de suas práticas, está exercendo este papel.

Enc. Bibli: R. Eletr. Bibliotecon. Ci. Inf., ISSN 1518-2924, Florianópolis, v. 15, n. 29, p.184-208, 2010. 


\section{METODOLOGIA}

Adotamos no presente estudo uma abordagem interpretativa, com base no pressuposto de que o grupo de indivíduos que compartilha determinada profissão - no caso, os bibliotecários produza construções também compartilhadas da realidade, que são passadas para outros indivíduos através do processo de socialização (BRADLEY, 1993, p. 433; WILLIAMSON, 2005, p. 85). Minayo (1999, p. 110) considera que "a identidade de condições de existência tende a reproduzir sistemas de disposições semelhantes, através de uma harmonização objetiva de práticas". Assim, os dados foram obtidos dos próprios bibliotecários, isto é, dos sujeitos da prática que se pretendia analisar.

$\mathrm{Na}$ coleta desses dados ouviram-se os bibliotecários de três maneiras diferentes. A primeira foi por meio de relatos escritos que elaboraram de suas práticas, ou seja, de idéias expressas pelos sujeitos, revelando sua linguagem singular, importante para a interpretação. A partir da base de dados LIBES $^{1}$, que reúne a produção bibliográfica brasileira sobre biblioteca escolar e que constitui a fonte mais abrangente de textos publicados sobre o assunto no país, foram identificados documentos que relatam ações implementadas por bibliotecários em escolas de ensino básico. Houve preocupação em selecionar relatos de autoria de bibliotecários, que descreviam experiências efetivamente realizadas, excluindo-se aqueles que constituíam apenas projetos. Assim, a menção a resultados obtidos foi condição para inclusão. Um primeiro levantamento na LIBES, abrangendo a década de 2000, identificou apenas seis relatos publicados, razão pela qual julgou-se necessário incluir uma monografia de especialização e um relatório de atividades de um sistema de bibliotecas - aos quais a pesquisadora teve acesso por meio dos autores - e mais cinco relatos produzidos em decorrência da participação de bibliotecários no Prêmio Carol Kuhlthau ${ }^{2}$ dos anos de 2006 e 2007. Esses sete relatos identificados fora da LIBES também foram submetidos aos mesmos critérios de inclusão

\footnotetext{
${ }^{1}$ A base de dados LIBES (Literatura Brasileira em Biblioteca Escolar), de responsabilidade do Grupo de Estudos em Biblioteca Escolar (GEBE), contém atualmente cerca de 400 referências, incluindo documentos publicados desde a década de 1960 . Está disponível em http://www.eci.ufmg.br/gebe/?LIBES

${ }^{2}$ O Prêmio Carol Kuhlthau foi conferido pela Autêntica Editora em parceria com o GEBE a projetos que tivessem utilizado a metodologia do livro "Como usar a biblioteca na escola", o qual propõe a aprendizagem de habilidades informacionais desde o início do período de escolarização e inclui sugestões de atividades para serem desenvolvidas na educação infantil e no ensino fundamental.
}

Enc. Bibli: R. Eletr. Bibliotecon. Ci. Inf., ISSN 1518-2924, Florianópolis, v. 15, n. 29, p.184-208, 2010. 
explicitados anteriormente. Buscando ampliar o número de relatos, de forma a se obter quantidade de dados que permitisse análise mais rica, optou-se por abranger também a década de 1990. Realizando-se o levantamento na LIBES, obtiveram-se mais sete relatos publicados ${ }^{3}$. Um exame preliminar do total de vinte documentos, de autoria de 18 bibliotecários ${ }^{4}$, revelou que os dados proporcionariam material adequado para a análise pretendida.

Os gêneros textuais representados foram: trabalhos apresentados em eventos (10), relatos do Prêmio Carol Kuhlthau (5), artigos de periódicos (2), monografia de especialização (1), capítulo de livro (1) e relatório de atividades (1). Embora constituindo gêneros textuais variados, os vinte relatos apresentavam uma forma discursiva relativamente estável, esclarecendo-se que aqueles provenientes do Prêmio Carol Kuhlthau haviam sido elaborados, por exigência do regulamento dos Prêmios, obedecendo a estrutura de relatos de experiência, em que os bibliotecários descreviam atividades desenvolvidas com os alunos, incluindo os resultados obtidos, o que atendeu aos critérios estabelecidos para a amostra. A distribuição dos relatos por ano e por gênero é apresentada no quadro a seguir

\begin{tabular}{c|c|l}
\hline ANO & QUANTIDADE & \multicolumn{1}{c}{ GÊNERO } \\
\hline 1991 & 1 & artigo de periódico \\
1999 & 6 & trabalhos apresentados em eventos \\
2000 & 1 & relatório de atividades \\
2003 & 1 & capítulo de livro \\
2004 & 1 & monografia de especialização \\
2005 & 5 & trabalhos apresentados em eventos \\
& & 1 artigo de periódico \\
2006 & 2 & relatos do Prêmio Carol Kuhlthau \\
2007 & 3 & relatos do Prêmio Carol Kuhlthau \\
\hline
\end{tabular}

Tabela 1: Distribuição dos relatos por ano e por gênero

A análise documental representou a primeira abordagem dos dados empíricos e possibilitou visualizar com mais clareza outros pontos a serem explorados em profundidade. A segunda maneira de ouvir os sujeitos foi por meio de entrevista semi-estruturada, feita com cinco bibliotecários: três de escolas públicas e dois de escolas particulares, de março a novembro de 2006. Foi uma amostra proposital, escolhida deliberadamente em função da riqueza de

\footnotetext{
${ }^{3}$ Desses, seis concentravam-se no ano de 1999, havendo, entretanto, um artigo de periódico do ano de 1991, incluído pelo fato de atender aos critérios estabelecidos para a amostra.

${ }^{4}$ Essa diferença se deve ao fato de que dois dos bibliotecários contribuíram com dois relatos.
}

Enc. Bibli: R. Eletr. Bibliotecon. Ci. Inf., ISSN 1518-2924, Florianópolis, v. 15, n. 29, p.184-208, 2010. 
informações que poderia oferecer (WILLIAMSON, 2005, p. 87) e beneficiando-se do conhecimento da pesquisadora, adquirido no longo contato com a área (BRADLEY, 1993, p. 444). Finalmente, com a finalidade de complementar os dados obtidos nas fontes documentais e nas entrevistas, formou-se um grupo de discussão, realizado no dia 20 de novembro de 2006, na Escola de Ciência da Informação da UFMG, reunindo cinco bibliotecários: três de escolas particulares e dois de escolas públicas. A escolha desses bibliotecários foi orientada pelos mesmos critérios que embasaram a escolha dos entrevistados, exceto que todos eram de escolas localizadas no município de Belo Horizonte.

Em síntese, compuseram a amostra 28 bibliotecários que atuavam em escolas de ensino básico, sendo 14 provenientes de escolas públicas e 14 de escolas particulares. Em termos de localização geográfica foram contemplados os seguintes Estados: Minas Gerais (13 informantes), São Paulo

(4), Santa Catarina (3), Espírito Santo (3), Paraná (1), Goiás (1), Rio de Janeiro (1), Maranhão (1), Pará (1). O período coberto foi de 1991 a 2007.

$\mathrm{Na}$ análise, houve preocupação com a descrição e interpretação das práticas, tentando-se compreender a realidade global do objeto de estudo (SUTTON, 1993, p. 420-421), tendo-se buscado capturar suas múltiplas relações, que foram analisadas com base nas noções apresentadas na revisão de literatura.

\section{ANÁLISE DOS RESULTADOS}

Foi possível perceber quatro finalidades da prática educativa do bibliotecário: (1) promoção da biblioteca; (2) promoção da leitura; (3) formação do leitor e (4) orientação da pesquisa escolar. Embora, neste artigo, tenham sido analisadas separadamente, na maior parte das vezes estavam interligadas. Inúmeras atividades eram desenvolvidas com esses fins em vista, resultando numa ação intensa do bibliotecário.

\subsection{Promoção da biblioteca}

Enc. Bibli: R. Eletr. Bibliotecon. Ci. Inf., ISSN 1518-2924, Florianópolis, v. 15, n. 29, p.184-208, 2010. 
Apesar de ser, freqüentemente, local de leitura mais convidativo que a sala de aula (SILVA, S. A., 1997), as bibliotecas pesquisadas enfrentavam diversas dificuldades para se firmar como espaço de freqüência regular dos usuários, o que levava os informantes a estar constantemente criando atividades de convencimento que denominamos de ações de promoção da biblioteca. Uma maneira de conquistar o usuário era proporcionando ambiente físico agradável e convidativo, buscando-se criar o que Nóbrega (2002, p. 130) chama de "ambiências de leitura", ou seja, um espaço agradável para leituras variadas na biblioteca. Era perceptível a convicção de que essa prática seria necessária para levar ao gosto pela leitura.

Além de atraente, a biblioteca precisava ser ativa e dinâmica, deixando para trás sua imagem de espaço amorfo e inerte. Havia preocupação de que as atividades da biblioteca ensejassem um clima de alegria, satisfação e humor, explorando-se o lado lúdico, como visto na fala a seguir:

"[A biblioteca deve ser] espaço vivo e atuante de que o usuário deve usufruir em toda sua potencialidade, pois além de servir como apoio no processo ensino-aprendizagem, constitui-se em lugar onde atividades lúdicas podem ser desenvolvidas, criando-se oportunidades de experiência cultural" (D 2)

Investindo no divertimento como forma de atrair usuários, as bibliotecas disponibilizavam jogos, realizavam brincadeiras e competições, organizavam gincanas, ofereciam prêmios e ofereciam atividades manuais como oficina de origami e confecção de livro de pano e outras desenvolvidas ao redor das narrativas, com a finalidade de dinamizar a leitura.

A persistência em atrair o usuário parece estar associada à necessidade de banir a imagem negativa da biblioteca e do bibliotecário que tem permeado a trajetória da instituição e da categoria. A vontade de mudar essa imagem ficou mais aparente quando a classe abraçou o conceito de marketing, a partir da década de 1970 (SILVEIRA; AMARAL, 1997, p. 25). Embora no presente estudo, o termo marketing apareça explicitamente na fala de apenas três dos 28 participantes, pode-se perceber a influência do conceito. Na literatura da área, o marketing aplicado à biblioteca tem sido tratado, em geral, como solução para o pretenso desconhecimento ou desinformação, por parte do público, da biblioteca e de seus "produtos", para o baixo uso do

\footnotetext{
${ }^{5}$ As falas dos informantes foram identificadas, utilizando-se o seguinte código:

$\mathrm{D}$ - fala proveniente de documento escrito (relato)

E - fala proveniente de entrevista

GD - fala proveniente do grupo de discussão
}

Enc. Bibli: R. Eletr. Bibliotecon. Ci. Inf., ISSN 1518-2924, Florianópolis, v. 15, n. 29, p.184-208, 2010. 
acervo e para a pouca freqüência e demanda dos serviços da biblioteca. De fato, o aspecto promocional do marketing é enfatizado pela maioria dos autores, que nele vêem um meio de aumentar a utilização do acervo e dos serviços, atrair recursos e "consumidores", sensibilizar o usuário para a importância da biblioteca. Alguns autores exploram a idéia do marketing como forma de criar laços afetivos entre a biblioteca e comunidade, contribuindo para firmá-la como espaço de cultura, lazer e convivência (SILVEIRA; AMARAL, 1997, p. 56). Esse enfoque pode ser observado na prática de participantes da pesquisa, que relataram atividades para inserir os estudantes no trabalho da biblioteca em projetos como: Bibliotecário por um dia e Aprendiz de bibliotecário, exposições de trabalhos escolares e artísticos dos estudantes, criação de mascote da biblioteca, exibição de fotos dos alunos em descanso de computadores. Percebe-se, nessas falas, a procura de comunicação com o usuário, a "interação com os consumidores por meio de um diálogo ativo e permanente" (Silveira e Amaral, 1997, p. 65).

\subsection{Promoção da leitura}

As ações dedicadas a atrair os usuários para a biblioteca estavam intimamente ligadas à promoção da leitura. Havia atividades específicas que buscavam "desenvolver atitude favorável diante da leitura" (D 8), "despertar e fortalecer o interesse pela leitura" (D 5), "despertar o gosto pela leitura e escrita" (D 14) e "incentivar o prazer da leitura" (D 1), utilizando inúmeras estratégias para convencer o estudante a ler (grifos nossos). Os participantes mencionaram constantemente suas atividades para "trazer o aluno para o fantástico mundo da leitura, ou se necessário, levar esse mundo até ele de maneira lúdica e prazerosa" (D 15), de "[...] promover a leitura no sentido de produzir satisfação e entusiasmo" (D 2); de criar “[...] ambiente propício, ao encontro do aluno com o livro, numa interação de prazer" (D 5).

Pode-se observar, por meio das falas, a convicção na possibilidade de a biblioteca desempenhar o que Perrotti (1990, p. 65) chamou de "papel redentor [da escola e da biblioteca] na luta para vencer a crise de leitura". Na maioria dos casos, não são mencionados "problemas estruturais intrínsecos ao modelo social vigente" e abstraem-se condições históricas que, na concepção do referido autor, estariam na origem da "crise de leitura" no país. Alguns informantes acreditavam que seria possível conquistar leitores, desde que se possuíssem as qualidades certas e se utilizassem as estratégias adequadas, como exemplificado na seguinte fala:

Enc. Bibli: R. Eletr. Bibliotecon. Ci. Inf., ISSN 1518-2924, Florianópolis, v. 15, n. 29, p.184-208, 2010. 
"Existem várias estratégias que podem ser utilizadas para apresentar o livro como objeto de prazer e está nas mãos dos educadores a tarefa de manter o encantamento natural da criança pelo livro, a fim de formarmos leitores" (D 11).

Alguns falaram sobre a influência de outros fatores nas deficiências de leitura, percebendo, por exemplo, que os estudantes precisavam de maior convivência com a leitura na família, ressaltando o papel do professor e reconhecendo que sozinho, o bibliotecário não teria condições de resolver o problema de leitura. Um informante explicou:

"É um projeto em que a gente vai tá trabalhando com o gosto pela leitura e convidando a família, por que a família é também um mediador na leitura, pra formação do pequeno leitor... Todo professor sabe que não é só a biblioteca" (E 1).

Ações de envolvimento da família eram integradas a outros aspectos da leitura: o lado atrativo, representado por um objeto que agrada à criança e o cuidado com o livro, como mostra a seguinte fala:

\footnotetext{
"A gente compra uma pastinha transparente que tem aquele elástico... Eles se sentem tão responsáveis com aquela pasta que é deles e que vai e volta e o pai assina, ou a mãe, o irmão, quem for, vai anotando atrás daquela folha os livros que eles vão lendo ou que alguém leu pra eles ...” (GD 1).
}

Utilizavam-se diversas estratégias para promover a leitura: usando o próprio mobiliário da biblioteca e improvisando com criatividade, garantindo "que o livro esteja ao alcance de nossos pequenos leitores, para que possam pegar, afagar, cheirar, manusear, folhear... o objeto desejado" (D 11). Outras estratégias mencionadas foram os prêmios para leitores mais assíduos e clube de leitura .

O esforço de desenvolver o gosto pela leitura marcava o papel de oito dos informantes como promotores de eventos: eles eram responsáveis por diversas atividades como feiras de livros e comemorações, que envolviam toda a escola, além de parcerias com agentes externos na realização de eventos relacionados à leitura. Essas ações propiciavam o envolvimento dos estudantes não só em atividades de leitura, mas de outras que os aproximaram de manifestações culturais variadas, como teatro, dramatização, música, filmes, desenho, pintura, fantoches. 
A descrição das práticas, feita acima, indica que grande parte das ações dos bibliotecários pesquisados estava voltada para o trabalho de convencimento dos usuários, tanto para freqüentar e usar a biblioteca como para gostar de ler, revelando riqueza das práticas e esforço para aproximar os alunos da biblioteca e superar problemas que se interpõem entre o livro e o leitor.

Assim, acreditando no potencial transformador da leitura, considerando-se responsáveis por promover seu acesso e mencionando apenas de passagem problemas estruturais a ela ligados, os participantes envidavam esforços para apresentar a leitura como algo agradável e prazeroso. Usando as armas de que dispunham, os bibliotecários empreendiam ações de dinamização que contrastam com as práticas pobres de leitura de sala de aula relatadas em pesquisas anteriores (MAGALHÃES, 1992, p. 175; SILVA, S. A. 1997, p. 96). Pareciam estar constantemente querendo neutralizar influências negativas que porventura os estudantes estivessem recebendo, e desenvolviam "estratégias" e "mecanismos" para tornar a leitura prazerosa, procurando "reduzir o atrito" de que fala Lajolo (1982, p. 14) ao criticar atividades de leitura lúdica na escola.

\subsection{Formação do leitor}

Os dados revelaram também outro nível da prática, no qual os bibliotecários se aproximavam do processo de formação do leitor. Nesse sentido, chamou especialmente atenção seu empenho em garantir que a leitura dos estudantes fosse livre de obrigações, de cobranças, dando-se ao usuário independência para escolher seus momentos de ler e o que queria ler.

Havia, nos relatos, firme crença de que a leitura obrigatória "pode provocar uma perigosa metamorfose: transformar crianças apaixonadas por livros em adolescentes/jovens/adultos em pessoas estressadas apenas com o fato de ter que ler um texto ou parte de algum livro" (D 11).

No grupo de discussão, essa questão desencadeou manifestações de participantes, que defenderam o direito de os estudantes escolherem suas leituras e que demonstraram saber que os próprios estudantes eram capazes de reconhecer quando faziam escolhas equivocadas. Um deles disse: "Eu prefiro deixar que ele descubra que não é o momento dele ler aquilo... Ele que tem que avaliar se é o momento dele ler agora, se ele vai dar conta" (GD 5).

Os dados parecem indicar que a defesa da liberdade de escolha de leituras feita pelos bibliotecários estaria relacionada ao princípio que norteia a profissão, que preconiza o amplo acesso à informação, concretizado, por exemplo, no princípio de livre acesso às estantes que 
permite, segundo Ranganathan (1963, p. 259, citado por RUBIN, 2004, p. 308), que o leitor "perambule entre os livros e pegue qualquer um de acordo com sua vontade e seu prazer". Foi possível notar claramente que os participantes estavam em direção oposta ao que é relatado em algumas pesquisas, que mostram o controle de leitura dos jovens pela escola e pela família (PINHEIRO, 2004, 118-119).

A garantia da liberdade de escolher leituras e a confiança no discernimento dos estudantes complementava-se com a abertura de possibilidades de que eles participassem da seleção do acervo, delineando-se aí um quadro que ressalta a característica marcante da profissão de garantir o acesso irrestrito à informação. Como explicou um participante do grupo de discussão:

“... temos uma tendência a sermos um pouco autoritários nas escolas de um modo geral... E essa fase não é o momento para isso, não em se tratando de leitura. Pelo menos eu percebi isso. Então, quando os alunos puderam me indicar títulos, puderam indicar coleções, aqueles que de fato indicaram aquelas coleções a leitura dentro da faixa etária melhorou" (GD 4).

Existia, portanto, na biblioteca, visível contraposição com as práticas de leitura observadas em sala de aula (MAGALHÃES, 1992, p. 175; SILVA, S. A.; 1997, p. 96). Nos relatos, o vilão que afastava os estudantes dos livros e levava ao desinteresse pela leitura era representado pelas "cobranças, provas e preenchimento de fichas" (D 16), que tranformam a literatura em "instrumento enfadonho de aprendizagem" (PACHECO, 2004, p. 210), constituindo o que Perrotti (1990, p. 65) caracterizou como "autoritarismo explícito das práticas escolares, especialmente as tradicionais" ou "modelos pedagógicos baseados na obediência do aluno a regras definidas pelo professor".

Alguns bibliotecários, mesmo acreditando que os estudantes tinham direito a escolher livremente suas leituras e implementando ações para que isso ocorresse, não se furtavam a indicar leituras quando eram solicitados, demonstrando que tinham papel destacado na orientação dos leitores para escolha de livros. Um dos participantes do grupo de discussão definiu bem sua posição de orientador de leitura na escola.

“Meu papel lá [na escola], já me enxergam como uma sugestão. Nem vão na estante. As crianças, os pais já chegam e falam assim ' $\mathrm{O}$ que você vai me dar para o fim de semana?" "(GD 5). 
Quatro participantes do grupo de discussão demonstraram conhecer fatores que influenciam a prática da leitura, como por exemplo o afastamento da leitura que ocorre tipicamente na $5^{\mathrm{a}}$ série, e três mostraram que conheciam as fases de formação do leitor, algumas características desse processo e entendiam que os usuários tendiam a querer ler o que o colega estava lendo.

A narrativa oral era freqüente na prática dos participantes, geralmente oferecida para crianças pequenas, funcionando na perspectiva da iniciação literária, com a finalidade de levar ao gosto pela leitura. Era usada para permitir à criança "introduzir-se no universo da literatura, viver uma experiência prazerosa" (D 8), representando o que Yunes (2002, p. 36-37) chama de "primeiras histórias", que se dão "sem pedagogismos", propiciando a "sedução do ouvir", substituindo, de certa forma, a família que, muitas vezes, não tem condições de fornecer as oportunidades de leitura nessa fase da trajetória de formação do leitor e lutando para evitar "o corte abrupto deste gozo da palavra no contexto escolar". Pode-se dizer que essas práticas de leitura dos bibliotecários estavam relacionadas com a vertente que Halliday (citado por COSSON, 2006, p. $47^{6}$ ) chamou de "aprendizagem $d a$ literatura", que significa "experienciar o mundo por meio da palavra". Nesse sentido, observou-se que os bibliotecários pesquisados contrapunham-se ao ensino tradicional da literatura que geralmente, segundo Cosson (2006, p. 47), ignoram esta vertente e enfatizam a "aprendizagem sobre a literatura" ("conhecimentos de história, teoria e crítica literária") e a "aprendizagem por meio da literatura" ("saberes e habilidades que a prática da literatura proporciona").

Embora com menos freqüência, esta última vertente foi também observada, quando as histórias narradas eram utilizadas como pretexto para trabalhar temas escolares, como meio ambiente, folclore, ética e para tratar de sentimentos, atitudes e valores morais que a escola precisa inculcar nos estudantes, como mostra a seguinte fala:

“... identificação pessoal e no grupo; afetividade; diferenças individuais; medo; autoritarismo; força, poder, violência (física e psicológica); desonestidade (corrupção e roubalheira: assunto levantado pelo interesse das crianças com o momento político que se passava no país ‘caso PC Farias'); companheirismo e amizade” (D 5).

Percebe-se que, embora demonstrando com veemência sua preocupação em trabalhar contrapondo-se às práticas de leitura obrigatória da sala de aula e esforçando-se o tempo todo

\footnotetext{
${ }^{6} \mathrm{O}$ texto de Cosson não inclui a referência do trabalho de Halliday.
} 
para tornar o ato de ler agradável e prazeroso, os informantes não se furtavam a usar as narrativas com objetivos práticos.

A narração de histórias desencadeava uma variedade de atividades, que mostraram a preocupação do bibliotecário com a dinamização, que mais uma vez reflete seu objetivo de atrair usuários e leitores: palestras, debates, concursos, jogos e gincanas, exposições e feiras, oficinas, cursos, dramatização, desenho, pintura; roda de discussões e debates; reprodução oral da história, a partir da leitura individual e em grupo; jogos e brincadeiras, adivinhações, jogos com palavras e figuras, tangram, dobraduras; produção de textos.

Observou-se que a mediação de leitura que ocorria na biblioteca era peculiar, ficando o interesse do leitor em primeiro plano, parecendo haver uma cumplicidade entre ele e o mediador, como pode ser visto na seguinte fala:

"O atendimento do usuário é exclusivo. O bibliotecário abandona o que estiver fazendo para atendê-lo. Conversamos sobre os livros expostos em estantes baixas, de livre acesso, trocamos idéias sobre o gênero literário de que ele mais gosta, sobre autores e ilustradores" (D 7).

As descrições feitas sobre promoção da biblioteca, promoção da leitura e formação do leitor expuseram um quadro de atividades rico e intenso que revelaram a extensão do trabalho do bibliotecário para aproximar os usuários do livro e da leitura.

Além dessas três, uma quarta vertente da prática educativa do bibliotecário emergiu dos dados, embora não com a mesma intensidade que caracterizou aquelas descritas anteriormente. Eram ações que envolviam a orientação da pesquisa escolar dos estudantes.

\subsection{Orientação da pesquisa}

Os dados mostraram, em primeiro lugar, que a orientação da pesquisa não é uma prática generalizada, pois foi mencionada por quinze dos 28 participantes, ao contrário das ações relativas à leitura, que foram relatadas pela totalidade dos sujeitos. Diferentemente das atividades ligadas à leitura, as de orientação da pesquisa não foram, em geral, descritas em detalhes - apenas três participantes descreveram com certa minúcia suas práticas de orientação de pesquisa.

Os problemas relativos à pesquisa escolar têm sido bastante mencionados na literatura, onde são descritos fatos que revelam a pobreza do processo, a prática do "trabalho-cópia" e a necessidade 
de mudar essa situação (MAGALHÃES, 1992, p. 181-185; MARTUCCI, 1997, p. 186-187; NEVES, 2000, p. 161; SILVA, S. A., 1997, p. 156).

Foi possível observar que alguns participantes estavam conscientes desses problemas. Um deles afirmou:

\begin{abstract}
"Quando eu cheguei aqui era só xerox, xerox, xerox. Deles [alunos] pegar o xerox e fazer um cartaz e colar. E eu disse: 'Olha, se eu fosse a professora, eu ia mandar vocês refazerem."” (E 3).
\end{abstract}

A orientação à pesquisa envolvia o ensino de três habilidades: seguir as etapas da pesquisa, usar fontes de informação e normalizar o trabalho escrito. As etapas da pesquisa e a normalização eram trabalhadas por meio de aulas e/ou fornecimento de roteiros. Pode-se observar que os participantes enfatizavam aspectos formais do trabalho e orientações sobre a apresentação e normalização estiveram presentes, revelando uma competência da esfera específica do bibliotecário.

O ensino do uso de fontes de informação foi descrito por diversos participantes: manuseio de enciclopédias, almanaques, periódicos, outras publicações; atividades para levar as crianças a se familiarizar com revistas, dicionários, enciclopédias, internet; ou livros de referência, livros técnicos, livros de ficção, biografias. Essa orientação envolvia geralmente duas estratégias: aulas expositivas e/ou orientação individual.

Três participantes tinham envolvimento sistemático com a orientação da pesquisa, trabalhando nos projetos junto com os professores, contribuindo com competências específicas: uso de fontes, normalização e partes do trabalho escrito. Procuravam reforçar a colaboração com os professores, construir um trabalho integrado com a sala de aula, tentando desenvolver não só a capacidade de pesquisa dos estudantes, mas também a conscientização dos professores para a importância de trabalhar com essa metodologia de pesquisa, exercendo o papel de catalizador da ação didática em torno da biblioteca (AASL/AECT, 1998, p. 50-55), como pode ser observado na seguinte fala:

“... todos os trabalhos que as professoras passam para as crianças, elas já vêm aqui na biblioteca, elas conversam comigo, pra tentar melhorar na questão da qualidade deles pesquisarem... A consciência do professor também melhorou. Antes eles pediam trabalho, trabalho... Hoje, o professor tá mais consciente. Tem professor que faz o trabalho com o aluno, ou eles levam o acervo para a sala de aula, ou então o professor 
vem com o aluno aqui na biblioteca. Então, o professor está interagindo junto com o aluno. Então, eu acho que isso melhorou bastante, até para o professor" (E 3).

As descrições feitas pelos participantes em geral, não permitiram definir com precisão o nível de envolvimento do bibliotecário, conforme explicitado por Kuhlthau (1996, p. 149-150), mas foi possível identificar sua ação como instrutor (quando ensina a usar as fontes necessárias a um trabalho solicitado pelo professor) e como tutor (quando orienta na elaboração do trabalho, mobilizando conhecimentos de sua esfera de competência).

A prática dos bibliotecários na orientação da pesquisa mostrou que eles estão contribuindo com saberes que dizem respeito especificamente à sua profissão. Percebendo que os professores têm dificuldades na implementação de estratégias didáticas relativas à aprendizagem por meio de informações, alguns informantes procuraram ocupar esse espaço, não só orientando os estudantes em áreas de sua competência, mas também estimulando mudanças no processo.

\section{CONSIDERAÇÕES FINAIS}

A sensibilização e a conquista dos estudantes constituem o principal foco da prática educativa dos bibliotecários. Os dados evidenciaram a predominância de ações voltadas para atrair os alunos para a biblioteca e para a leitura, comprovada também pelo vigor e detalhamento com que os participantes descreveram, nas entrevistas, as atividades de promoção da biblioteca, do livro e da leitura.

É importante esclarecer que as atividades de promoção da biblioteca estão, na maior parte das vezes, ligadas à promoção da leitura, isto é, o bibliotecário quer atrair os usuários para a biblioteca e para o livro. Ele investe em aspectos tais como, criação de ambiência acolhedora e em atividades de entretenimento (jogos, trabalhos manuais), visando tornar o aluno leitor. Fica claro que os bibliotecários estão engajados na luta pela melhoria da capacidade de leitura dos estudantes, utilizando os instrumentos de que dispõem (espaço da biblioteca, estratégias peculiares, flexibilidade de ação, coleção variada).

Das duas ações típicas que ocorrem na biblioteca, ligadas mais diretamente à formação do leitor indicação de leitura e trabalho com a narrativa oral - a última acontece com mais freqüência, já que permite a exploração da leitura por meio de atividades de dinamização, o que remete mais 
uma vez às idéias de liberdade/prazer/acolhimento, que estimulam a freqüência à biblioteca e a leitura. A ênfase na dinamização e na promoção de eventos evidenciada pelos dados é um ponto que poderia ser objeto de aprofundamento em futuros estudos, com base em conceitos de entretenimento e de espetacularização, que já têm fundamentado estudos nas áreas de política, religião, mídia, esportes e educação e não têm sido explorados na biblioteconomia.

A quantidade de atividades de orientação à pesquisa é bem mais modesta, se comparada às de promoção da biblioteca e da leitura. Considerando-se que aprendizagem pela pesquisa orientada é o espaço por excelência para o letramento informacional (KUHLTHAU; MANIOTES; CASPARI, 2007, p.1), pode-se concluir que, nesse sentido, a ação dos bibliotecários é incipiente. Embora reconhecendo a importância da questão e sua responsabilidade com relação a ela, não conseguiram em geral sistematizar ações coletivas e permanentes que distinguem a noção de letramento informacional.

Além de proporcionar maior compreensão sobre o papel educativo que o bibliotecário brasileiro vem desempenhando, os dados possibilitaram formar uma noção do patamar em que se encontra sua prática educativa em relação ao estado-da-arte. É visível a distância entre as práticas aqui desenvolvidas e o conceito de letramento informacional conforme relatado na literatura. Ficou patente a preocupação central dos bibliotecários com a leitura que, de resto, é também questão que tem mobilizado grande parcela dos educadores e sido objeto de políticas educacionais que tentam encontrar formas de melhorar a capacidade de leitura de crianças e jovens no Brasil. É perfeitamente compreensível então que o bibliotecário tome parte ativa nesse esforço, prestando sua contribuição peculiar. Considerando que a competência em leitura seja fator básico para o letramento informacional, pode-se dizer que a prática do bibliotecário brasileiro encontra-se em patamar que antecede ao letramento informacional. Alguns bibliotecários estão engajados em atividades que mostram seu entendimento da necessidade de formar pessoas com capacidade de aprender com a informação, de pesquisar corretamente, de serem aprendizes autônomos, mas ainda precisam percorrer etapas para fazê-lo de forma completa. Entretanto, considerando-se que mesmo em países adiantados há dificuldades para levar a biblioteca escolar a se transformar em espaço de aprendizagem questionadora, pode-se compreender o grau de dificuldade que os bibliotecários brasileiros têm de enfrentar, devendo superar não apenas a carência de recursos, mas a tradição pedagógica fundada em métodos instrucionistas de aprendizagem (DEMO, 2005, p. 85). 
A partir da análise feita, torna-se oportuno observar que a comunidade acadêmica e os pesquisadores da área de biblioteconomia, ciência da informação e educação poderiam oferecer contribuição substantiva ao debate sobre letramento informacional no Brasil ao se debruçarem sobre questões específicas da realidade do país, buscando construir noções de letramento informacional que realmente ajudem a fortalecer o papel educativo do bibliotecário nas escolas brasileiras.

Ao captar a visão do bibliotecário sobre suas práticas, esta pesquisa mostrou um dos ângulos da questão. Ao se ampliar esse foco em futuros estudos, que incluam olhares de outros atores (alunos, professores, dirigentes, etc.), será possível uma compreensão mais abrangente da dinâmica da biblioteca escolar, que poderá sustentar de forma mais firme as necessárias ações políticas da classe em busca de melhores condições de funcionamento das bibliotecas escolares brasileiras.

\section{REFERÊNCIAS}

AMBINDER, D. M. et al. Biblioteca escolar e cidadania: uma revisão de literatura. In: CONGRESSO BRASILEIRO DE BIBLIOTECONOMIA, DOCUMENTAÇÃO E CIÊNCIA DA INFORMAÇÃO, 21., 2005, Curitiba. Anais ... Curitiba: Associação Bibliotecária do Paraná/FEBAB, 2005. CD-ROM.

AMERICAN ASSOCIATION OF SCHOOL LIBRARIANS/ ASSOCIATION FOR EDUCATIONAL COMMUNICATIONS AND TECHNOLOGY. Information power: building partnerships for learning. Chicago: ALA, 1998.

AMERICAN LIBRARY ASSOCIATION. Presidential Committee on Information Literacy. Final report.

Chicago, 1989.

$<$ http://www.ala.org/ala/acrl/acrlpubs/whitepapers/presidential.htm> Acesso em: 12 fev. 2006.

BARROS, M. H. T. C. Presença de elementos pedagógicos nos serviços biblioteconômicos. 1987. Dissertação. (Mestrado em Biblioteconomia) - Curso de Pós-Graduação em Biblioteconomia, Pontifícia Universidade Católica de Campinas, Campinas.

BRADLEY, J. Methodological issues and practices in qualitative research. Library Quarterly, v. 63 , n. 4, p. 431-449, 1993. 
CAMPELLO, B. A função educativa da biblioteca escolar no Brasil: perspectivas para seu aperfeiçoamento. In: ENCONTRO NACIONAL DE PESQUISA EM CIÊNCIA DA INFORMAÇÃO, 5., 2003, Belo Horizonte. Anais ... Belo Horizonte: Escola de Ciência da Informação da UFMG, 2003. CD-ROM.

CAMPELLO, B. et al. Literatura sobre biblioteca escolar: características de citações de teses e dissertações brasileiras. Transinformação, Campinas, v. 19, n. 3, p. 227-236, 2007. Disponível em: http://revistas.puc-campinas.edu.br/transinfo/index.php Acesso em: 07 fev. 2008.

COSSON, R. Letramento literário. São Paulo: Contexto, 2006.

DEMO, P. Saber pensar. 4. ed. São Paulo: Cortez/ Instituto Paulo Freire, 2005. 159 p.

DIOS, C. M. L. A. A dinamização da leitura na biblioteca escolar. 1989. Dissertação (Mestrado em Educação) - Faculdade de Educação, Universidade Federal Fluminense, Niterói.

FIALHO, J. F.; MOURA, M. A. A formação do pesquisador juvenil. Perspectivas em Ciência da Informação, Belo Horizonte, v. 10, n. 2, p. 194-207, 2005.

GASQUE, K. C. G. D.; TESCAROLO, R. Letramento informacional e os desafios da educação básica. In: CONGRESSO BRASILEIRO DE BIBLIOTECONOMIA, DOCUMENTAÇÃO E CIÊNCIA DA INFORMAÇÃO, 22., 2007, Brasília. Anais ... Brasília: FEBAB/ABDF, 2007. CD-ROM.

KUHLTHAU, C. C. Seeking meaning: a process approach to library and information services. Norwood, NJ.: Ablex, 1996. 199 p.

KUHLTHAU, C.; MANIOTES, L.; CASPARI, A. Guided inquiry: learning in the $21^{\text {st }}$ century. Westport: Libraries Unlimited, 2007.

LAJOLO, M. Do mundo da leitura para a leitura do mundo. 3. ed. São Paulo: Ática, 1997. O texto não é pretexto. In: ZILBERMAN, R. (Org.). Leitura em crise na escola. Porto Alegre: Mercado Aberto, 1982. Citado por SILVA, E. T. Leitura na escola e na biblioteca. Campinas: Papirus, 1995. 
MAGALHÃES, M. H. A. Leitura recreativa na escola de $\mathbf{1}^{\circ}$ grau da rede oficial municipal de ensino de Belo Horizonte. 1980. Dissertação (Mestrado em Administração de Bibliotecas) Escola de Biblioteconomia, Universidade Federal de Minas Gerais, Belo Horizonte.

. Uma leitura ... da leitura na escola de primeiro grau. 1992. (Doutorado em Educação) - Faculdade de Educação, Universidade de São Paulo, São Paulo.

MARTUCCI, E. M. Processo educativo na mediação da informação em biblioteca pública: um estudo fenomenológico. Revista de Biblioteconomia de Brasília, Brasília, v. 21, n. 2, p. 167$187,1997$.

MINAYO, M. C. S. O desafio do conhecimento: pesquisa qualitativa em saúde. Rio de Janeiro: Hucitec/Abrasco, 1999.

MORIGI, V. J.; VANZ, S. A. S.; GALDINO, K. O bibliotecário e suas práticas na construção da cidadania. Rev. ABC: Biblioteconomia em Santa Catarina, Florianópolis, v. 7, n. 1, p. 134$147,2002$.

NEVES, I. C. Bitencourt. Pesquisa escolar nas séries iniciais do ensino fundamental: bases para um desempenho interativo entre sala de aula e biblioteca escolar. 2000. Tese (Doutorado em Ciência da Informação e Documentação) - Escola de Comunicações e Artes, Universidade de São Paulo, São Paulo.

NOBREGA, N. G. De livros e bibliotecas como memória do mundo: dinamização de acervos. In: YUNES, E. (Org.). Pensar a leitura: complexidades. Rio de Janeiro: Ed. PUC-Rio; São Paulo: Loyola, 2002. p. 120-135.

PACHECO, P. S. A linguagem literária: sua especificidade e seu papel. In: PAIVA, A. et al. Democratizando a leitura: pesquisas e práticas. Belo Horizonte: Ceale/Autêntica, 2004. p. 207 218.

PERROTTI, E. Confinamento cultural, infância e leitura. São Paulo: Summus, 1990.

PINHEIRO, M. P. Reflexões sobre práticas de letramento literário de jovens: o que é permitido ao jovem ler? In: PAIVA, A. et al. Democratizando a leitura: pesquisas e práticas. Belo Horizonte: Ceale/Autêntica, 2004. p. 111-120. 
RANGANATHAN. S. R. The five laws of library science. New York: Asia, 1963. Citado por RUBIN, R. Foundations of library and information science. $2^{\text {nd }}$. ed. New York: Neal-Schuman Publishers, 2004. 581 p.

RUBIN, R. Foundations of library and information science. $2^{\text {nd }}$. ed. New York: NealSchuman Publishers, 2004. 581 p.

SALES, F. O bibliotecário escolar na rede municipal de ensino de Florianópolis (SC). In: CONGRESSO BRASILEIRO DE BIBLIOTECONOMIA, DOCUMENTAÇÃO E CIÊNCIA DA INFORMAÇÃO, 21., 2005, Curitiba. Anais. Curitiba: Associação Bibliotecária do Paraná, 2005. CD-ROM.

SILVA, E. T. Leitura na escola e na biblioteca. Campinas: Papirus, 1995.

Leitura e realidade brasileira. 5. ed. Porto Alegre: Mercado Aberto, 1997.

SILVA, S. A. Práticas e possibilidades de leitura na escola. 1997. Dissertação (Mestrado em Educação) - Faculdade de Educação, Universidade Federal de Minas Gerais, Belo Horizonte.

SILVEIRA, A.; AMARAL, S. A. Marketing em unidades de informação: estudos brasileiros. Brasília, 1993. 365 p.

SUTTON, B. The rationale for qualitative research: a review of principles and theoretical foundations. Library Quarterly, v. 63, n. 4, p. 411-430, 1993.

VIANNA, M. M.; CALDEIRA, P. T. Literatura sobre biblioteca escolar: análise dos trabalhos apresentados no Seminário Biblioteca Escolar Espaço de Ação Pedagógica. In: SEMINÁRIO BIBLIOTECA ESCOLAR ESPAÇO DE AÇÃO PEDAGÓGICA, 3., 2004, Belo Horizonte. Trabalhos apresentados. Belo Horizonte: Grupo de Estudos em Biblioteca Escolar, Associação dos Bibliotecários de Minas Gerais, 2004. Disponível em: $<$ http://www.eci.ufmg.br/gebe/downloads/301.pdf> Acesso em: 20 jan. 2007.

WILLIAMSON, K. Research in constructivist frameworks using ethnographic techniques. Library Trends, v. 55, n. 1, p. 83-101, 2006.

WOOLLS, B. Understanding the multiple faces of literacy: librarian as reading innovator and developer of thinking skills. In: ANNUAL CONFERENCE OF THE INTERNATIONAL ASSOCIATION OF SCHOOL LIBRARIANSHIP, 35., 2006, Lisboa. IASL reports 2006. Lisboa: IASL, 2006. CD-ROM. 
YUNES, E. Leitura, a complexidade do simples: do mundo à letra e de volta ao mundo. In: . (Org.). Pensar a leitura: complexidades. Rio de Janeiro: Ed. PUC-Rio; São Paulo: Loyola, 2002.

\begin{abstract}
This research aims to understand the educational practice of Brazilian school librarians, seeking to clarify: whether this practice is restricted to the promotion of reading, if librarians are involved in teaching informational skills and in what extent they are contributing to student's information literacy. Analysis was made based on a qualitative/interpretative approach. The sample group was made up of 28 librarians, 14 of them from government schools and 14 from private schools, from nine different states. Data were collected through reports, interviews and group discussion. Results showed that the main focus of the librarian educational practice is on attracting students to the library and reading. Librarians' performance in regard to the research process proves true the assumption that there is an incipient action toward the practice of information literacy in Brazilian school libraries, but librarians still need to move further in order to contribute effectively to develop student's information literacy.
\end{abstract}

Keywords: School librarians. Information literacy. Educational practices.

Originais recebidos em:

Aceito para publicação em: 